\title{
Assessing Adequacy of a Probability Distribution for Estimation of Design Flood
}

\author{
N. Vivekanandan
}

\begin{abstract}
Estimation of design flood for a desired return period is of prime importance for safe design of hydraulic structures such as dams, spillways, bridges, culverts, urban drainage systems and flood plain zoning. Frequency analysis enables estimation of the probability of occurrence of a certain hydrological event of practical importance by fitting a probability distribution to one that is empirically obtained from recorded annual maximum discharge (AMD) data. This study deals with the fitting of Extreme Value Type-1, Gamma, 2-parameter Lognormal (LN2) and Log Pearson Type-3 (LP3) distributions to the AMD data; and examines the use of goodness-of-fit tests and diagnostic analysis in assessing the adequacy of suitable probability distribution for estimation of design flood. Results of the study showed that LN2 distribution is better suited for modelling flood data for Tapi at Burhanpur, Girna at Dapuri and Bori at Malkheda sites; and LP3 is the best for Purna at Lakhpuri.
\end{abstract}

Keywords--- Anderson-Darling, Chi-Square, D-Index, Probability Distribution, Frequency Analysis, KolmogorovSmirnov, Design Flood

\section{INTRODUCTION}

$\mathrm{I}_{\mathrm{g}}^{\mathrm{N}}$ NFORMATION on flood magnitudes and their frequencies generally forms one component of the design parameter for safe and economical design of structures such as dams, spillways, road/ railway bridges, culverts, urban drainage systems, flood plain zoning and flood protection projects. Flood frequency analysis is identified as an effective and expedient tool for estimation of design flood. The procedure enables estimation of the probability of occurrence of a certain hydrological event of practical importance by fitting a theoretical probability distribution to one that is empirically obtained from recorded data [1].

The three main steps involved in frequency analysis are: selection of a sample in the form of a data series that satisfies certain statistical criteria; fitting the best theoretical probability distribution to represent the sample, using the best fitting technique available for the distribution; and using the fitted distribution to make statistical inferences about the underlying population. Past experiences of research workers with extreme value analysis of rainfall and flood data indicated that the probability distributions such as Extreme Value Type-1 (EV1), 2-parameter Gamma (G2), 2-parameter
Log Normal (LN2), Log Pearson Type-3 (LP3) to be alternative choices for arriving at a design parameter [2-7]. When different distribution models are used for modelling an Annual Maximum Discharge (AMD) data series, a common problem that arises is how to determine which model fits best for a given set of data. This can be answered by formal statistical procedures involving goodness-of-fit and diagnostic tests; and the results are quantifiable and reliable than those from the empirical procedures.

Qualitative assessment is made from the plot of the recorded and estimated flood discharge. For quantitative assessment on flood data within in the recorded range, Goodness-of-Fit (GoF) tests like Anderson-Darling (A2), Chisquare $\left(\chi^{2}\right)$ and Kolmogorov-Smirnov (KS) are applied. Diagnostic analysis involving D-index is used in upper tail region for selection of the best probability distribution for modelling flood data [8-9]. The objective of the paper is to assess the adequacy of a probability distribution for estimation of design flood with some illustrative examples.

\section{Methodology}

The study considers the use of four probability distributions, namely EV1, G2, LN2 and LP3 in flood modelling, and illustrates the applicability of GoF test procedures in identifying which distributional model is best for the specific data. Table 1 gives the Probability Density Function (PDF) with the corresponding flood estimator (QT) of EV1, G2, LN2 and LP3 distributions used in modelling flood data.

GoF tests are either based on Cumulative Distribution Function (CDF) or PDF. $\chi^{2}$-test is based on PDF, and $\mathrm{A}^{2}$ and $\mathrm{KS}$ tests are based on CDF approach; and hence belong to the class of distance tests [10-11]. In addition to the above, Dindex is used to assess the adequacy of fitting distributions to the recorded AMD data in the upper tail region. The test essentially gives weightage to the upper most six data points only, rather than the data points at lower levels, with the designated objective of checking the suitable distribution for estimation of flood for extrapolation [12-14]. Table 2 gives the theoretical descriptions of GoF tests used in the study. 
Table 1: PDF with Flood Estimator of EV1, G2, LN2 and LP3 Distributions

\begin{tabular}{|l|l|l|}
\hline \multicolumn{1}{|c|}{ Distribution } & \multicolumn{1}{|c|}{ PDF } & $\mathrm{Q}_{\mathrm{T}}$ \\
\hline EV1 & $\mathrm{f}(\mathrm{q}: \alpha, \mathrm{m})=\frac{\mathrm{e}^{-(\mathrm{q}-\mathrm{m}) / \alpha} \mathrm{e}^{-\mathrm{e}^{-(\mathrm{q}-\mathrm{m}) / \alpha}}}{\alpha}$ & $\mathrm{Q}_{\mathrm{T}}=\mathrm{m}+\mathrm{Y}_{\mathrm{T}} \alpha$ \\
\hline G2 & $\mathrm{f}(\mathrm{q} ; \alpha, \lambda)=\frac{\mid \alpha \mathrm{e}^{-\alpha \mathrm{q}}(\alpha \mathrm{q})^{\lambda-1}}{\Gamma(\lambda)}, \mathrm{q}>0, \alpha, \lambda>0$ & $\mathrm{Q}_{\mathrm{T}}=\left(\frac{1}{\alpha}\right)\left(\mathrm{K}_{\mathrm{T}} \sqrt{\lambda}+\lambda\right)$ \\
\hline LN2 & $\mathrm{f}(\mathrm{q} ; \alpha, \lambda)=(1 / \lambda \mathrm{q} \sqrt{2 \pi}) \exp \left[-(\ln \mathrm{q}-\alpha)^{2} / 2 \lambda^{2}\right]$ & $\mathrm{Q}_{\mathrm{T}}=\operatorname{Exp}\left(\alpha+\lambda \mathrm{K}_{\mathrm{T}}\right)$ \\
\hline LP3 & $\mathrm{f}(\mathrm{q} ; \alpha, \lambda, \mathrm{m})=\frac{|\alpha|}{\Gamma(\lambda)}\left(\frac{\mathrm{e}^{\alpha \mathrm{m}}}{\mathrm{q}^{1+\alpha}}\right)[\alpha(\ln \mathrm{q}-\mathrm{m})]^{\lambda-1}$ & $\mathrm{Q}_{\mathrm{T}}=10^{\mathrm{m}+\left(\left(\lambda+\mathrm{K}_{\mathrm{p}} \sqrt{\lambda}\right) / \alpha\right)}$ \\
\hline
\end{tabular}

Table 2: Theoretical Description of GoF Test Statistics

\begin{tabular}{|c|l|l|}
\hline GoF test & \multicolumn{1}{|c|}{ Test statistics } & \multicolumn{1}{c|}{ Selection criteria } \\
\hline$\chi^{2}$ & $\chi^{2}=\sum_{\mathrm{j}=1}^{\mathrm{NC}} \frac{\left.\mathrm{R}_{\mathrm{j}}(\mathrm{q})-\mathrm{E}_{\mathrm{j}}(\mathrm{q})\right)^{2}}{\mathrm{E}_{\mathrm{j}}(\mathrm{q})}$ & $\begin{array}{l}\text { If the computed value of GoF test statistics of the } \\
\text { distribution is less than that of theoretical value at } \\
\text { the desired significance level then the selected } \\
\text { distribution is accepted to be adequate than any } \\
\text { other distribution for modelling flood data. }\end{array}$ \\
\hline $\mathrm{A}^{2}$ & $\mathrm{~A}^{2}=(-\mathrm{N})-(1 / \mathrm{N}) \sum_{\mathrm{i}=1}^{\mathrm{N}}\left\{(2 \mathrm{i}-1) \log \left(\mathrm{Z}_{\mathrm{i}}\right)+(2 \mathrm{~N}+1-2 \mathrm{i}) \log \left(1-\mathrm{Z}_{\mathrm{i}}\right.\right.$ \\
\hline $\mathrm{KS}$ & $\mathrm{KS}=\operatorname{Max}_{\mathrm{i}=1}^{\mathrm{N}}\left(\mathrm{F}_{\mathrm{e}}\left(\mathrm{q}_{\mathrm{i}}\right)-\mathrm{F}_{\mathrm{D}}\left(\mathrm{q}_{\mathrm{i}}\right)\right)$ & $\begin{array}{l}\text { The distribution having the least value for D-index } \\
\text { is considered as the best distribution for estimation } \\
\text { of design flood for a desired return period. }\end{array}$ \\
\hline D-index & $\overline{\overline{\mathrm{Q}}} \sum_{\mathrm{i}=1}^{6}\left|\mathrm{Q}_{\mathrm{i}}-\mathrm{Q}_{\mathrm{i}}^{*}\right|$ & \\
\hline
\end{tabular}

\section{APPLICATION}

The methodology detailed above is applied to assess the adequacy of the probability distributions of EV1, G2, LN2 and LP3 for estimation of flood for Tapi at Burhanpur, Girna at
Dapuri, Purna at Lakhpuri and Bori at Malkheda sites. AMD data recorded at the respective sites during the period 19772004 are used. Table 3 gives the statistical parameters of the recorded AMD data [15].

Table 3: Statistical Parameters for Original and Log-Transformed Series of Recorded AMD

\begin{tabular}{|l|r|r|r|r|r|r|r|r|}
\hline \multirow{2}{*}{$\begin{array}{c}\text { Gauging } \\
\text { site }\end{array}$} & \multicolumn{9}{|c|}{ Statistical parameters based on } \\
\cline { 2 - 10 } & \multicolumn{1}{|c|}{$\begin{array}{c}\text { Original series } \\
\left(\mathrm{m}^{3} / \mathrm{s}\right)\end{array}$} & $\begin{array}{c}\text { Std. Dev. } \\
\left(\mathrm{m}^{3} / \mathrm{s}\right)\end{array}$ & $\begin{array}{c}\text { Coeff. of } \\
\text { skewness }\end{array}$ & $\begin{array}{c}\text { Coeff. of } \\
\text { kurtosis }\end{array}$ & $\begin{array}{c}\text { Mean } \\
\left(\mathrm{m}^{3} / \mathrm{s}\right)\end{array}$ & $\begin{array}{c}\text { Std. Dev. } \\
\left(\mathrm{m}^{3} / \mathrm{s}\right)\end{array}$ & $\begin{array}{c}\text { Coeff. of } \\
\text { skewness }\end{array}$ & $\begin{array}{c}\text { Coeff. of } \\
\text { kurtosis }\end{array}$ \\
\hline Burhanpur & 8079.1 & 6731.8 & 1.491 & 1.867 & 8.672 & 0.853 & -0.200 & -0.337 \\
\hline Dapuri & 602.0 & 850.1 & 2.521 & 7.370 & 5.516 & 1.435 & 0.043 & -0.923 \\
\hline Lakhpuri & 788.3 & 515.2 & 0.418 & -1.010 & 6.347 & 0.989 & -1.424 & 2.142 \\
\hline Malkheda & 118.0 & 124.6 & 1.748 & 2.658 & 4.242 & 1.099 & -0.059 & -0.956 \\
\hline
\end{tabular}

\section{RESUlTS AND Discussions}

\section{A. Estimation of Design Flood using Probability Distributions}

A computer program was developed and used to fit the recorded AMD data to the EV1, G2, LN2 and LP3 distributions. The program computes the Maximum Likelihood Method (MLM) parameters of the distributions, design flood estimates for different return periods, GoF tests and diagnostic values. The MLM parameters were further used to develop the CDF plots for the data under study and delineated in Figure 1. The design flood estimates for different return periods given by EV1, G2, LN2 and LP3 distributions for Burhanpur, Dapuri, Lakhpuri and Malkheda sites are given in Table 4.
From Table 4, it may be noted that the LN2 distribution gave higher estimates for return period above 10-year (yr) consistently when compared with corresponding values of other three distributions for the data under study. Figure 2 shows the plots of recorded and estimated flood discharge for different return periods obtained using EV1, G2, LN2 and LP3 for river Tapi and three of its tributaries at the respective sites. 
Table 4: Design flood estimates given by EV1, G2, LN2 and LP3 distributions for Burhanpur, Dapuri, Lakhpuri and Malkheda

\begin{tabular}{|c|c|c|c|c|c|c|c|c|c|c|c|c|c|c|c|c|}
\hline \multirow{2}{*}{$\begin{array}{c}\text { Return } \\
\text { period } \\
(\mathrm{yr})\end{array}$} & \multicolumn{16}{|c|}{ Estimated design flood $\left(10^{3} \mathrm{~m}^{3} / \mathrm{s}\right)$ using } \\
\hline & \multicolumn{4}{|c|}{ EV1 } & \multicolumn{4}{|c|}{ G2 } & \multicolumn{4}{|c|}{ LN2 } & \multicolumn{4}{|c|}{ LP3 } \\
\hline 2 & 6.99 & 0.46 & 0.71 & 0.10 & 6.38 & 0.32 & 0.62 & 0.08 & 5.84 & 0.25 & 0.57 & 0.07 & 6.20 & 0.29 & 0.71 & 0.08 \\
\hline 10 & 16.70 & 1.69 & 1.45 & 0.23 & 16.82 & 1.56 & 1.64 & 0.27 & 17.08 & 1.51 & 1.98 & 0.28 & 16.62 & 1.54 & 1.55 & 0.27 \\
\hline 20 & 20.41 & 2.16 & 1.73 & 0.29 & 21.01 & 2.15 & 2.05 & 0.36 & 23.16 & 2.53 & 2.82 & 0.41 & 21.26 & 2.24 & 1.74 & 0.37 \\
\hline 50 & 25.21 & 2.77 & 2.10 & 0.36 & 26.44 & 2.96 & 2.57 & 0.47 & 32.62 & 4.50 & 4.19 & 0.60 & 27.56 & 3.28 & 1.91 & 0.49 \\
\hline 500 & 37.12 & 4.27 & 3.01 & 0.52 & 39.74 & 5.05 & 3.87 & 0.75 & 65.06 & 14.38 & 9.33 & 1.55 & 44.11 & 6.20 & 2.10 & 0.83 \\
\hline 1000 & 40.69 & 4.72 & 3.28 & 0.58 & 43.69 & 5.69 & 4.25 & 0.83 & 77.70 & 19.39 & 11.46 & 1.95 & 49.24 & 7.11 & 2.13 & 0.93 \\
\hline & & & & & & & $\mathrm{D}$ & 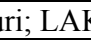 & & $M$ & Mollt & & & & & \\
\hline
\end{tabular}

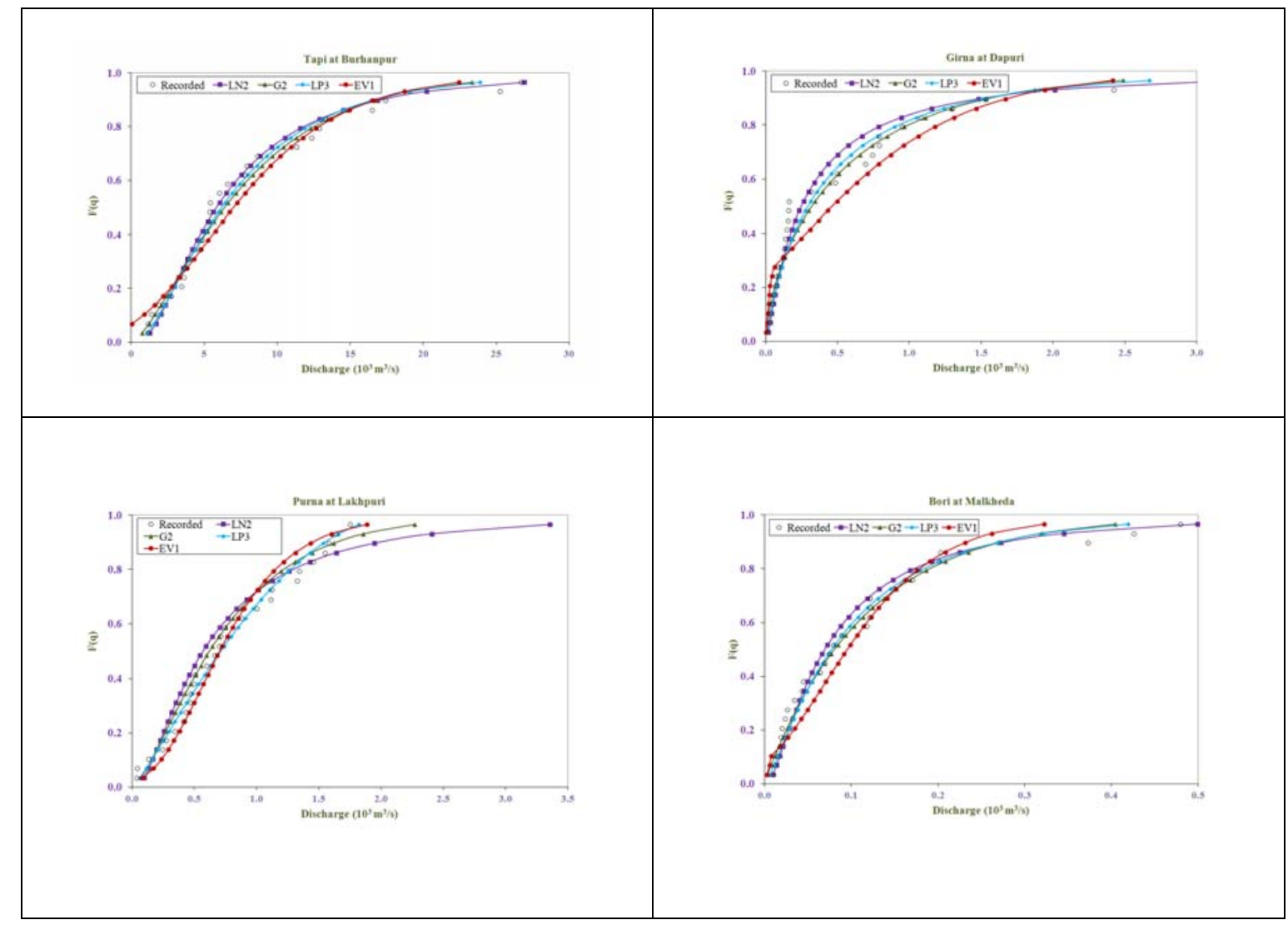

Figure 1: CDF Plots of Recorded and Estimated Flood Discharge Using EV1, G2, LN2 and LP3 Distributions

\section{B. Quantitative Analysis}

\section{B1. Analysis based on GoF Tests}

For the assessment on fitting of probability distributions to the recorded AMD data series, GoF test statistics for four distributions were computed and given in Table 5. In the present study, degrees of freedom for all four distributions were considered as four while computing $\chi 2$ statistics values for the data under study.

From Table 5, it may be noted that the computed values of $\chi 2$ statistics of EV1 distributions is greater than the theoretical values at 5\% level of significance, and hence at this level, EV1 is not found suitable to fit the recorded AMD data at Dapuri site. Also, from Table 5, it may be noted that the A2 test doesn't support the use of EV1 for modelling flood data for Dapuri and Malkheda; and LN2 for Lakhpuri. On the other hand, A2 test supports the use of EV1, G2 and LP3 for modelling flood data recorded at Burhanpur and Lakhpuri.

Also, from Table 5, it may be noticed that KS test confirms the use of all four distributions for estimation of flood for river Tapi and three of its tributaries at the respective sites 
Table 5: Computed Values of GoF Test Statistics for EV1, G2, LN2 and LP3 Distributions

\begin{tabular}{|c|c|c|c|c|c|c|c|c|c|c|c|c|}
\hline \multirow[t]{3}{*}{ Distribution } & \multicolumn{12}{|c|}{ Computed values of GoF test statistics for } \\
\hline & \multicolumn{4}{|c|}{$\chi^{2}$} & \multicolumn{4}{|c|}{$\mathrm{A}^{2}$} & \multicolumn{4}{|c|}{$\mathrm{KS}$} \\
\hline & BUR & DAP & LAK & MAL & BUR & DAP & LAK & MAL & BUR & DAP & LAK & MAL \\
\hline EV1 & 7.357 & 23.071 & 0.929 & 3.786 & 0.672 & 1.951 & 0.482 & 1.016 & 0.146 & 0.251 & 0.116 & 0.141 \\
\hline $\mathrm{G} 2$ & 3.071 & 7.714 & 1.643 & 1.286 & 0.309 & 0.595 & 0.504 & 0.354 & 0.107 & 0.185 & 0.120 & 0.090 \\
\hline LN2 & 1.286 & 5.214 & 2.357 & 2.357 & 0.257 & 0.421 & 1.050 & 0.360 & 0.085 & 0.152 & 0.157 & 0.116 \\
\hline LP3 & 0.929 & 5.929 & 1.286 & 2.714 & 0.244 & 0.461 & 0.257 & 0.311 & 0.099 & 0.182 & 0.084 & 0.099 \\
\hline
\end{tabular}

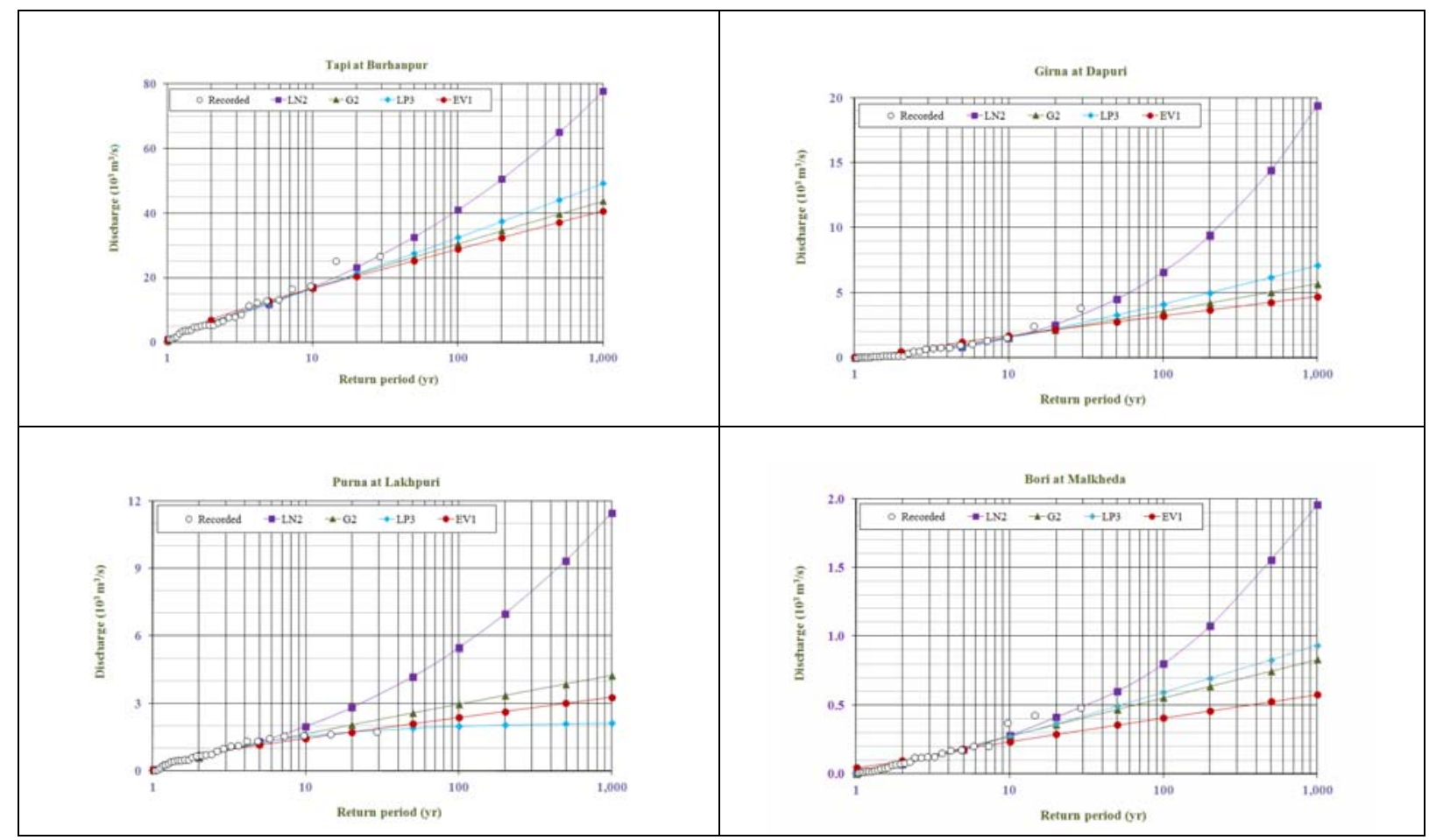

Figure 2: Plots of Recorded and Estimated Flood Discharge using EV1, G2, LN2 and LP3 Distributions

\section{B2. Diagnostic Analysis}

With the objective of giving more weightage to the data points in the upper tail region, since extrapolation is of prime importance in frequency analysis of flood data, D-index test is applied to assess the adequacy of suitable probability distribution for the data under study. Table 6 gives the Dindex values of four distributions for the data under study.

Table 6: D-index Values for EV1, G2, LN2 and LP3 Distributions

\begin{tabular}{|l|c|c|c|c|}
\hline \multirow{2}{*}{$\begin{array}{c}\text { Gauging } \\
\text { site }\end{array}$} & \multicolumn{4}{|c|}{ Indices of D-index for } \\
\cline { 2 - 5 } & EV1 & G2 & LN2 & LP3 \\
\hline Burhanpur & 1.722 & 1.582 & 1.170 & 1.620 \\
\hline Dapuri & 4.409 & 3.233 & 2.454 & 3.060 \\
\hline Lakhpuri & 1.261 & 1.488 & 3.735 & 0.576 \\
\hline Malkheda & 4.064 & 2.850 & 2.088 & 2.576 \\
\hline
\end{tabular}

From Table 6, it may be noticed that the indices of D-index of LN2 are minimum when compared with the corresponding values of other three distributions for Burhanpur, Dapuri and Malkheda though KS test support the use of all four distributions to fit the recorded AMD data. Also, from Table
6 , it may be noticed that the value of D-index given by LP3 is minimum for Lakhpuri and considered to be a good choice for modelling flood data. From the results of GoF tests and diagnostic analysis, it transpires that LN2 distribution is better suited for modelling flood data for Tapi at Burhanpur, Girna at Dapuri, Bori at Malkheda sites and LP3 is better suited for Purna at Lakhpuri.

\section{Qualitative Analysis}

A qualitative assessment of the goodness of fit is ascertainable from the plot of the recorded and estimated flood discharge by suitable probability distribution. Figure 3 shows the plots of recorded and estimated flood discharge given by LN2 for Burhanpur, Dapuri and Malkheda; and LP3 for Lakhpuri together with confidence limits at $95 \%$ level for the sites under study. From Figure 3, it can be seen that the recorded AMD data falls within the confidence limits of the estimated values given by the selected distribution for river Tapi and three of its tributaries at the respective sites. The results indicated that the percentages of error in estimated flood discharge using LN2 distribution for Burhanpur, Dapuri and Malkheda are about 3\%, 4\% and 5\% respectively. The result also indicated that the percentage of error in estimated 
flood discharge using LP3 is $7 \%$ for Lakhpuri. The study showed that the percentages of uncertainty in flood estimation for the sites are within the acceptable tolerance limit of $\pm 10 \%$ [16].

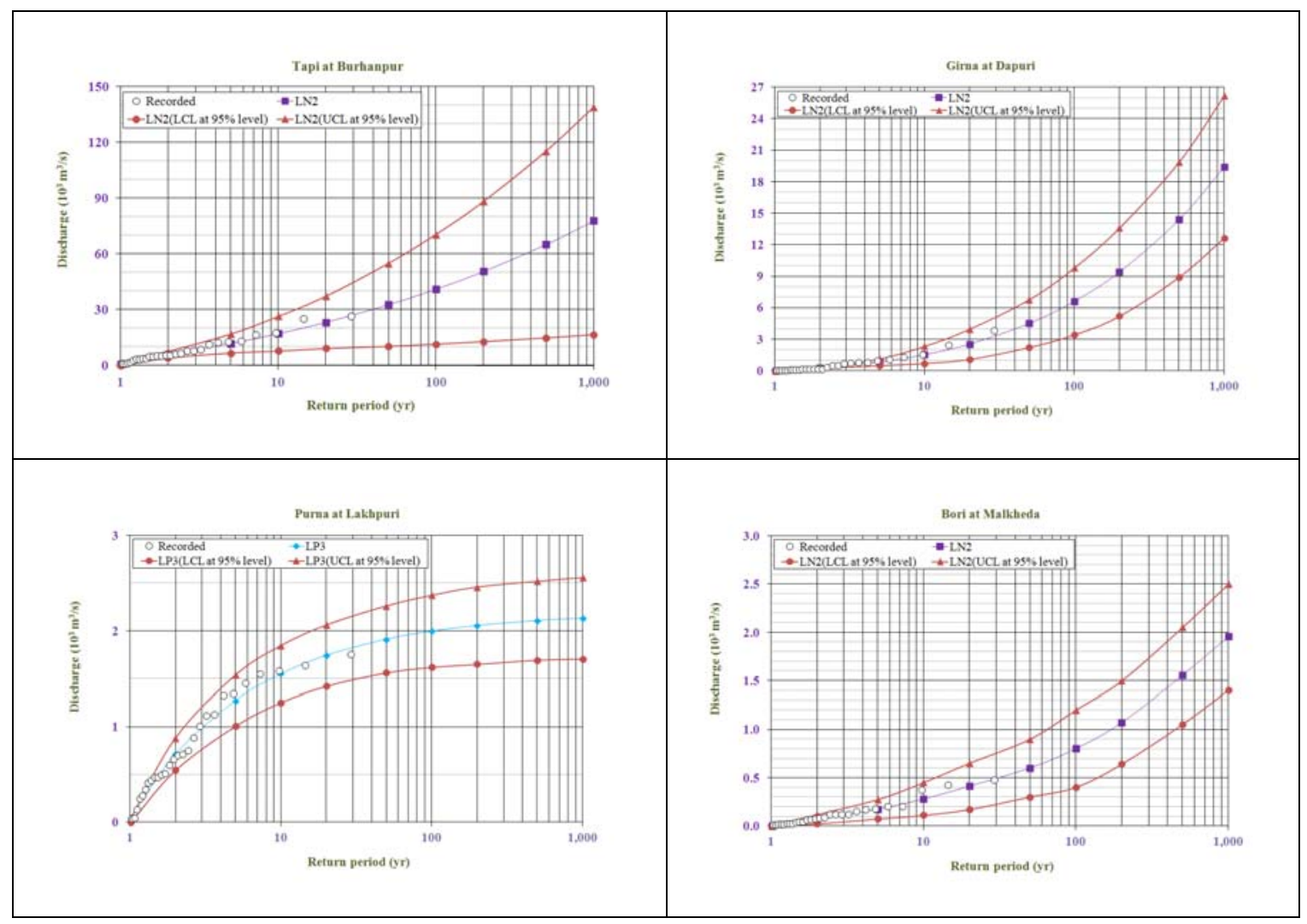

Figure 3: Plots of Recorded and Estimated Flood Discharge given by the Selected Distributions Together with Confidence Limits at $95 \%$ Level

\section{CONCLUSIONS}

The paper presented a study on assessing adequacy in fitting of EV1, G2, LN2 and LP3 distributions in flood modelling using GoF tests and diagnostic analysis. The results of GoF tests uniformly supported the use of LN2 and LP3 distributions for modelling flood data for the sites under study. The results of diagnostic analysis showed that LN2 distribution is better suited for estimation of flood for Tapi at Burhanpur, Girna at Dapuri, Bori at Malkheda sites and LP3 for Purna at Lakhpuri. The study showed that the percentages of error in estimated discharge using LN2 for Burhanpur, Dapuri and Malkheda are about 3\%, 4\% and 5\% respectively; and about 7\% when LP3 is used for Lakhpuri. The methodology reported in the paper is expected to be of assistance to stakeholders for planning, design and development of hydraulic structures at the respective sites of river Tapi and three of its tributaries.

\section{ACKNOWLEDGMENTS}

The author is grateful to the Director, Central Water and Power Research Station, Pune, for providing the research facilities to carry out the study. The author is thankful to the Executive Engineer (Tapi Division), Central Water
Commission, Gujarat, for making available the streamflow data to carry out the study.

\section{REFERENCES}

[1] Atomic Energy Regulatory Board (AERB), Extreme values of meteorological parameters (Guide No. NF/SG/ S-3), 2008.

[2] W. May, "Variability and extremes of daily rainfall during the Indian summer monsoon in the period 1901-1989", Global and Planetary Change, Vol. 44, Nos.1-2, Pp 83-105, 2004.

[3] V.N. Sharda and P.K. Das, "Modelling weekly rainfall data for crop planning in a sub-humid climate of India", Agricultural Water Management, Vol. 76, No. 2, Pp 120-138, 2005.

[4] J. A. Carta and P. Ramirez, "Analysis of two-component mixture Weibull statistics for estimation of wind speed distributions", Renewable Energy, Vol. 32, Pp 518-531, 2007.

[5] V.B.Vaidya, B.I. Karande, Pandey Vyas, M.M. Lunagaria and A.M. Shekh, "Rainfall probability analysis for crop planning in Gujarat state", Journal of Agrometeorology, Vol. 10, Nos. 1-2, Pp 183-185, 2008.

[6] R. Rao and H. K. Hamed, Flood Frequency Analysis, M/s CRC Publications, New York, London, 2000.

[7] J.H. Lee and J.H. Heo, "Evaluation of estimation methods for rainfall erosivity based on annual precipitation in Korea", Journal of Hydrology, Vol. 409, Nos. 1-2, Pp 30-48, 2011.

[8] J. Suhaila and A.A. Jemain, "Fitting Daily Rainfall Amount in Peninsular Malaysia using Several Types of Exponential Distributions", Journal of Applied Sciences Research, 3 (10), 10271036, 2007.

[9] P.P. Sreekala, S. Vijaya Bhaskara Rao and M. Rajeevan, "Northeast monsoon rainfall variability over south peninsular India and its teleconnections", Journal of Theoretical and Applied Climatology, Vol. 
108, Nos. 1-2, Pp 73-83, 2012.

[10] A. H. Ang and W. H. Tang, Probability concepts in engineering planning and design, Vol. 2, Decision, Risk and Reliability, John Wiley \& Sons, 1984.

[11] U.C. Roman, P.D. Porey, P.L. Patel and N. Vivekanandan, "Assessing Adequacy of Probability Distributional Model for Estimation of Design Storm", ISCA Journal of Engineering Sciences, Vol. 1, No. 1, Pp 19-25, 2012.

[12] D'Agostino B. Ralph and Stephens A. Michael, Goodness of Fit Statistic, M/s Marcel Dekkar Inc., New York \& Basel, 1986.

[13] J. Zhang, "Powerful goodness-of-fit tests based on the likelihood ratio", Journal of Royal Statistical Society, Vol. 64, No.2, Pp 281-294, 2002.

[14] United States Water Resources Council (USWRC), Guidelines for Determining Flood Flow Frequency, Bulletin No.17B, Pp15-19, 1981.

[15] CWC, Report on availability of streamflow data for gauging sites in Tapi river basin, Central Water Commission, Tapi division, Gujarat, 2006.

[16] ISO 5168, Measurement of fluid flow - Estimation of uncertainty of a flow rate measurement, Bureau of Indian Standards, 1978.

Notations:

\begin{tabular}{|c|c|c|}
\hline $\mathrm{R}_{\mathrm{j}}(\mathrm{q})$ & $=$ & Recorded frequency value of AMD of $\mathrm{j}^{\text {th }}$ class \\
\hline$\alpha$ & $=$ & Scale parameter \\
\hline $\bar{\lambda}$ & $=$ & Shape parameter \\
\hline $\mathrm{m}$ & $=$ & Location parameter \\
\hline $\mathrm{C}_{\mathrm{S}}$ & $=$ & Coefficient of skewness \\
\hline$E_{i}(q)$ & $=$ & Expected frequency value of AMD of $\mathrm{j}^{\text {th }}$ class \\
\hline $\mathrm{F}\left(\mathrm{q}_{\mathrm{i}}\right)$ & $=$ & CDF of $q_{i}$ \\
\hline $\mathrm{F}_{\mathrm{D}}\left(\mathrm{q}_{\mathrm{i}}\right)$ & $=$ & Computed CDF of $\mathrm{q}_{\mathrm{i}}$ \\
\hline $\mathrm{F}_{\mathrm{e}}\left(\mathrm{q}_{\mathrm{i}}\right)$ & $=$ & Empirical CDF of $\mathrm{q}_{\mathrm{i}}$ with $\mathrm{F}_{\mathrm{e}}\left(\mathrm{q}_{\mathrm{i}}\right)=(\mathrm{i}-0.35) / \mathrm{N}$ \\
\hline $\mathrm{K}_{\mathrm{P}}$ & $=$ & $\begin{array}{l}\text { Frequency factor corresponding to } \mathrm{C}_{\mathrm{S}} \text { of log- } \\
\text { transformed series of recorded data for LP3 }\end{array}$ \\
\hline $\mathrm{K}_{\mathrm{T}}$ & $=$ & $\begin{array}{l}\text { Frequency factor corresponding to } C_{S} \text { with } \\
C_{S}=2 / \sqrt{\lambda} \text { for } G 2 \text { and } C_{S}=0.0 \text { for LN } 2\end{array}$ \\
\hline $\mathrm{N}$ & $=$ & Number of observations \\
\hline $\mathrm{NC}$ & $=$ & Number of frequency classes \\
\hline $\mathrm{p}$ & $=$ & Number of parameters of distribution \\
\hline $\mathrm{Y}_{\mathrm{T}}$ & $=$ & Reduced variate where $\mathrm{Y}_{\mathrm{T}}=-\mathrm{Ln}[-\operatorname{Ln}(1-(1 / \mathrm{T}))]$ \\
\hline$Z_{\mathrm{i}}$ & $=$ & $\mathrm{F}\left(\mathrm{q}_{\mathrm{i}}\right)$, for $\mathrm{i}=1,2,3, \ldots \mathrm{N}$, and $\mathrm{q}_{1}<\mathrm{q}_{2}<\mathrm{q}_{3}<\ldots \mathrm{q}_{\mathrm{N}}$ \\
\hline
\end{tabular}

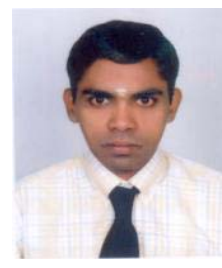

N. Vivekanandan (June 1969) post graduated in mathematics from Madurai Kamaraj University in 1991. $\mathrm{He}$ obtained post graduate degree in hydrology from University of Roorkee in 2000 and master of philosophy degree in mathematics from Bharathiar University in 2006. From May 1993 to March 2006, he worked as Research Assistant and analyzed hydrometeorological data using statistical methods for water related studies. From April 2006 to till date, he is working Assistant Research Officer wherein carrying out hydrological studies using statistical and deterministic approaches, prediction of hydrometeorological variables using soft computing techniques and optimization of hydrometric network using spatial regression approach and information theory for various water resources projects. 